\title{
A PROPOSED METHOD FOR THE ASSESSMENT OF THE INTERACTIVE HEAVY METAL ACCUMULATION IN SOILS
}

\author{
PAPAIOANNOU D. ${ }^{1}$ \\ KALAVROUZIOTIS I.K. ${ }^{1, *}$ \\ KOUKOULAKIS P. ${ }^{2}$ \\ PAPADOPOULOS F. ${ }^{2}$
}

Received: 03/10/2015

Accepted: $15 / 11 / 2015$

Available online: $26 / 11 / 2015$

\author{
${ }^{1}$ School of Science and Technology, Hellenic Open University \\ Aristotelous 18, 26 335, Patras, Greece \\ 2Hellenic Agricultural Organization "Demetra" \\ Soil Science Institute, Thermi, Thessaloniki, Greece
}

*to whom all correspondence should be addressed: e-mail: ikalabro@eap.gr

\section{ABSTRACT}

A method is proposed for the assessment of the interactive accumulation of heavy metals in soils. Sixty surface soil samples were collected from fifteen sites, at a depth of 0-30 cm, evenly distributed, within the 30,700 ha comprising the study area.

It was found that at least some of these metals were significantly contributed to soil, i.e. Mn 9.53, Fe 8.06, Zn 0.86, Pb 0.29, Cd 0.033, Co 0.112 and $\mathrm{Ni} 0.125 \mathrm{~kg} / \mathrm{ha}$, respectively.

Similarly considerable levels of plant nutrients were accumulated in the studied soil such as $\mathrm{P}_{2} \mathrm{O}_{5}$ 8.6, or $3.75 \mathrm{~kg} \mathrm{P} / \mathrm{ha}, \mathrm{K}_{2} \mathrm{O} 52.92$ or $43.94 \mathrm{~kg} \mathrm{~K} / \mathrm{ha}$, and $\mathrm{Ca} 78.98 \mathrm{~kg} / \mathrm{ha}$. As expected, the heavy metals accumulated in lower concentrations than those of plant nutrients and in non toxic levels. Nevertheless, the toxicity of these metals must be considered in relation to long term accumulation.

It was shown that the proposed method, based on the quantification of the elemental interactions contribution in heavy metals, could be used as a tool for the quantitative assessment of their accumulation and for the prediction of the «silent pollution» that gradually occurs in soils with these metals.

Keywords: Soil, heavy metal accumulation, assessment of elemental interactions, heavy metal pollution.

\section{Introduction}

Soil is a very complex and open natural system, and as a part of the terrestrial ecosystem, plays a significant role in elemental cycling. It has important functions as a filter and as a buffer system, and also, as a storage of heavy metals, plant nutrients and other complex compounds, and transformation system, supporting a homeostatic interrelationship between the biotic and abiotic environments (Kabata-Pendias, 1993).

In soils, as well as in plants, numerous interactions may take place between macro-, micro-nutrients and heavy metals and the soil physical and chemical properties (Kalavrouziotis and Koukoulakis, 2012; Kalavrouziotis et al., 2008; Ntzala et al., 2013.). The intensity of these interactions depends on the soil characteristics ( $\mathrm{pH}, \mathrm{CEC}, \mathrm{OM}, \mathrm{Clay}$, Fe and Mn oxides, redox potential), plant (species, cultivar, part or age) and environmental factors (climate, irrigation, topography, management practices) (Kabata-Pendias and Andriano, 1995).

Papaioannou D., Kalavrouziotis I.K., Koukoulakis P. and Papadopoulos F. (2015), A proposed method for the assessment of the interactive heavy metal accumulation in soils, Global NEST Journal, 17(4), 835-846. 
The interactions between these elements seem to play an important role in supplying the soil with heavy metals and plant nutrients, although their mechanism is not very well understood. A number of factors may cause their occurrence (Kalavrouziotis and Koukoulakis, 2009). This accumulation could lead to a dynamic heavy metal «silent pollution» of soils, the adverse effects of which could possibly appear in the long run, provided that no anthropogenic pollution will take place.

Research work contacted during the last 10 years in the Department of Environmental and Natural Resources Management of the University of Ioannina, Greece, showed that the elemental interactions contribute significant amounts of heavy metals, and plant nutrients depending on the extent of synergism and antagonism that occurs between these elements (Kalavrouziotis and Koukoulakis, 2012). That is why the interactions could act as plant growth and soil fertility factors and as a means affecting favorably or adversely the environmental quality, (Kalavrouziotis and Koukoulakis, 2009).

Generally, among the interactions, the synergistic ones are on the average predominating over the antagonistic. This predominance is directly related to soil fertility and plant growth positively and negatively, depending on the kind of element being supplied. Similarly, the antagonistic interactions may have positive or negative effect depending on whether the element deprived is heavy metal or plant nutrient. The fact is that in either case the elemental interactions are directly related to the environmental quality, and hence to the economy (Koukoulakis et al., 2013; Kalavrouziotis et al., 2012).

The various soil inputs such as fertilizers, treated wastewater, and sewage sludge, seem to increase the number of interactions occurring in soils, irrespective of the extent of their pollution (Kalavrouziotis et al., 2010).

The actual use as a method for the study and assessment of the contribution to soils by the elemental interactions in terms of heavy metals $(\mathrm{Co}, \mathrm{Cr}, \mathrm{Cd}, \mathrm{Cu}, \mathrm{Zn}, \mathrm{Mn}, \mathrm{Pb})$ or of plant nutrients $(\mathrm{P}, \mathrm{K}, \mathrm{Ca}, \mathrm{Mg})$ under natural or anthropogenic conditions, to our knowledge, has not so far been studied quantitatively by any investigator.

Voluminous information has accumulated during the last years about the heavy metals toxic effect, their non-biodegegradable nature, the risk effect possed on human, animal and plant health and the accumulation of these metals, and metalloids in soils, water and atmosphere as a result of the anthropogenic activities, which have caused significant environmental health problems in many countries.

The analysis of the above problem of heavy metals is outside of the scope of this paper.

Nevertheless, the aim of the present study is to examine the possibility of using the "elemental interactions" as a method for assessing their contribution in terms of heavy metals, under the effect of soil properties i.e. $\mathrm{pH}$, electrical conductivity, organic matter, $\mathrm{CaCO}_{3}$, and clay, in order to predict the possibility of future soil pollution with these toxic heavy metals.

\section{Materials and methods}

\subsection{Study area and soil sampling}

The study area is in Peloponnese, Greece, geographically determined by the coordinates: longitude $21^{\circ} 31^{\prime}$ - $21^{\circ} 49^{\prime} \mathrm{E}$ and latitude $37^{\circ} 49^{\prime}-37^{\circ} 35^{\prime} \mathrm{N}$, and its boundaries encompass a total area of 30,700 ha. The climate of the area is characterized by a Mediterranean type with mild and rainy winter. The area is cultivated with currant vines, horticultural crops mainly citrus trees, wheat and forage. The geological formations of the study area include alpine formations mainly consisting of sandstone, pelitic, marl, limestone, siltstone, siliceous formations, sandy and silt-clayey (I.G.M.E., 2003).

The soil samples originated from fifteen uncultivated sites evenly distributed in the above area). The names of the specific sites are reported in Figure 1. Four soil samples per site were taken at a depth of 0$30 \mathrm{~cm}$ and the distance among the sampling points was $2 \mathrm{~km}$. A total of 60 soil samples of approximately $1 \mathrm{~kg}$ wt were taken i.e. $4 \times 15=60$ samples. 


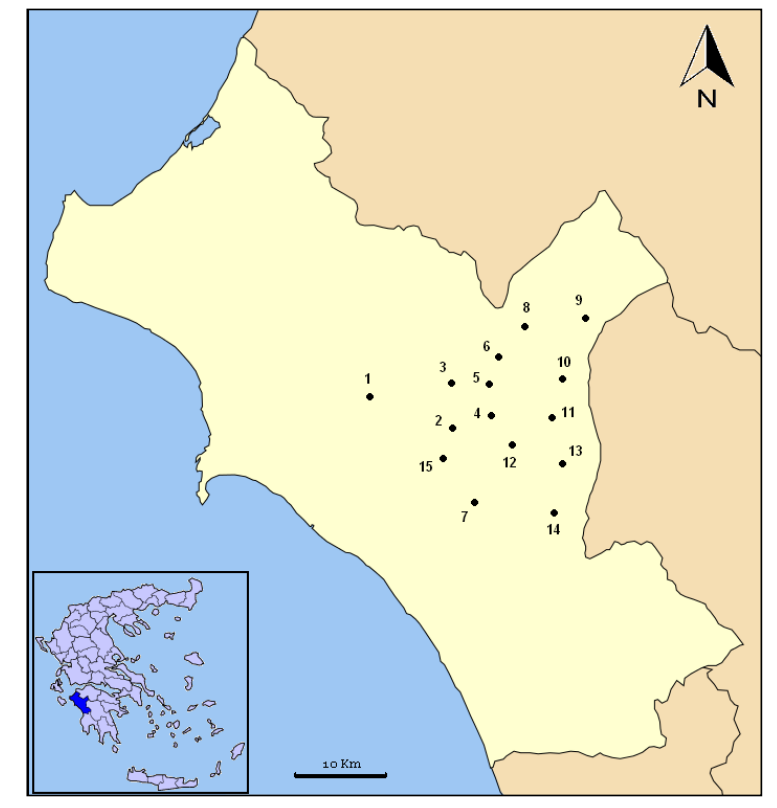

Figure 1. Map of study area in Elias Prefecture

The fifteen sites on (Fig. 1) are 1.Sopi-Karatoula, 2.Pothos, 3.Douca, 4.Lala, 5.Milies, 6.Persaina, 7.Mouria, 8.Foloe, 9.Koumani, 10.Axlathini, 11.Nemounda, 12.Vilia, 13.Xerokambos, 14.Basilaki and 15.Diliza.

\subsection{Soil analysis}

The soil samples were air-dried and sieved through a $2 \mathrm{~mm}$ sieve, oven dried, at $100^{\circ} \mathrm{C}$ and were analyzed by means of internationally-accepted classical methods, as follows: soil mechanical analysis by Bouyoucos method (Bouyoucos, 1951), organic matter by the wet digestion procedure of Walkley and Black (Jackson, 1958), $\mathrm{CaCO}_{3}$ by the method of Bernard, $\mathrm{pH}$ was measured on water extract of saturated paste using a standard glass pH electrode and the conductivity t by means of a conductivity meter (Jackson, 1958). Available soil $P$ was analyzed by Olsen et al. (1954) method, the extracting agent being $0,5 \mathrm{~N} \mathrm{NaHCO}_{3}$ and $\mathrm{P}$ was measured spectrophotometrically. The exchangeable $\mathrm{Ca}^{2+}, \mathrm{Mg}^{2+}, \mathrm{K}^{+}$, and $\mathrm{Na}^{+}$by extraction with $\mathrm{NH}_{4} \mathrm{Ac} \mathrm{pH} 7.0$ (Lanyon and Heald, 1982), $\mathrm{Ca}$ and Mg by titrating with Versenate (Richards, 1954), also $\mathrm{K}$ and $\mathrm{Na}$ by flame photometer. Micronutrients $\mathrm{Zn}, \mathrm{Fe}, \mathrm{Mn}$, and $\mathrm{Cu}$ and heavy metals $\mathrm{Cd}, \mathrm{Pb}, \mathrm{Co}, \mathrm{Ni}$, and $\mathrm{Cr}$ were extracted with DTPA (Lindsay and Norvell, 1978) and measured by inductively coupled plasma emission spectroscopy (ICP-ES) (Soltanpour et al., 1998). The relevant results of soil analysis are reported in Tables 1, 2 and 3.

\subsection{Statistical analysis and the Procedure of quantification of the elemental interactions contribution}

The statistical processing of the experimental data was made by Microsoft SPSS ver. 20, and Excel 2002. It included ANOVA, regression analysis and determination of Pearson's correlation

The elemental concentration data were used for the procedure of quantification and determination of percent elemental contribution of (PEC) according to the modified procedure of Koukoulakis et al., (2013), which is explained below as follows:

1-The rational of the procedure of quantification of the elemental interactions contribution, is based on the usually found difference in elemental concentration of soil samples taken from randomly distributed points of a given field. This difference in the concentration of a given element between two soil samples, taken from two randomly distributed sites of the same field, is due to the effect of variability of some known factors, such as $\mathrm{pH}, \mathrm{CaCO}_{3}$, organic matter, clay mineral composition, oxides of $\mathrm{Fe}, \mathrm{Mn}$, and $\mathrm{Al}$, moisture, presence of various other elements, and also to the effect of the elemental interactions, which may play an important role. Naturally, other unknown factors may also be involved. 
The question which is raised is: What is the percent contribution, of the elemental interactions occurring in soil, in this difference?

2-To answer this question, it is necessary to have an extensive analytical soil data of the concentration of the basic heavy metals , plant nutrients and data of soil physical and chemical properties, so that it can be possible to run regression analysis among these factors, with the view to determine all the statistically significant elemental interactions.

It must be mentioned in this respect, that in the soil numerous interactions may take place, which can be represented by linear, logarithmic or quadratic relationship, but obviously, not all of these regression equations are statistically significant. They have to be chosen, based on the regression coefficient, the significance of the NOVA F value, and the general shape of the interactions response curve, which in most cases it is quadratic, secondarily logarithmic and rarely linear.

Assume that we want to calculate the interactions contribution in terms of $\mathrm{Zn}$. Let us consider that the following interactions are statistically significant, i.e. $E_{1} \times Z n_{1}, E_{2} \times Z n_{2}, \ldots E_{n} \times Z n_{n}$ where $E_{1}, E_{2}, \ldots E_{n}$ represents various elements. Further, we consider that, these interactions are expressed by the following statistically significant regression quadratic equations:

The interaction $E_{1} \times Z n$ represented by the equation $Z n=\alpha_{1}\left(E_{1}\right)^{2} \pm \beta_{1}\left(E_{1}\right) \pm \gamma_{1}$

The interaction $E_{2} x Z n$ represented by the equation $Z n=\alpha_{2}\left(E_{2}\right)^{2} \pm \beta_{2}\left(E_{1}\right) \pm \gamma_{2}$,

The interaction $E_{n} x Z n$ represented by the equation $Z n=\alpha_{n}\left(E_{n}\right)^{2} \pm \beta_{n}\left(E_{1}\right) \pm \gamma_{n}$

From the available analytical data of soil, the maximum and minimum values of the elements $E_{1}, E_{2} \ldots . . . E_{n}$ are known. Also the maximum and minimum value of $\mathrm{Zn}$ is found.

By solving the above equations for the maximum and minimum value of $E_{1}, E_{2} \ldots . . . E_{n}$, (independent variable) respectively, the theoretical or calculated maximum and minimum values of the dependent variable $Z n$ । is determined. The difference between $\left(Z n_{\max }-Z n_{\min }\right)$, or $\left(Z n_{\max }-Z n_{\min }\right)$ or $\left(Z n_{\max }-Z n_{\min }\right)$ represents the calculated contribution in terms of $Z n$ of the interactions $E_{1} \times Z n_{1}, E_{2} \times Z n_{2}$ and $E_{n} \times Z n_{n}$, respectively.

Since Zinc is the dependent variable in the regression equations, the above can be expressed by the following general relationship, which actually represents the Percent Elemental Contribution (PEC), (Koukoulakis et al. 2013) i.e.:

$$
\operatorname{PEC}=\left(y_{\text {maxcl }}-y_{\text {mincl }}\right) \times 100 /\left(y_{\text {maxan }}-y_{\text {minan }}\right)
$$

where $\left(y_{\text {maxcl }}\right)$ represents the calculated maximum value of the dependent variable in $\mathrm{mg} \mathrm{kg}^{-1}$, and $\left(y_{\text {mincl }}\right)$ represents the calculated minimum value of the dependent variable in $\mathrm{mg} \mathrm{kg}^{-1}$. The $\left(\mathrm{y}_{\text {maxan }}\right)$ represents the maximum value of the dependent variable obtained from the set of the existing analytical data of soil (in $\left.m g ~ \mathrm{~kg}^{-1}\right)$, and $\left(\mathrm{y}_{\operatorname{minan}}\right)$ represents the minimum value of the dependent variable, obtained from the set of the existing analytical data of soil analysis (in $\mathrm{mg} \mathrm{kg}^{-1}$ ).

Finally, the PEC is calculated as the mean value of the algebraic sum of the individual PECs corresponding to each of the above regression equations, divided by the number of equations or the number of interactions, which in this case are 3 . It must be noted that the value of PEC can be positive is most of the interactions are mainly synergistic or negative if the antagonistic interactions dominate.

The positive PEC means that the interactions supplied the soil with the corresponding element and contribute to its accumulation, while the negative PEC means that the interactions decreased the element under consideration by the respective value of PEC.

\section{Results and Discussion}

\subsection{Soil physicochemical characteristics}

The physicochemical characteristics of soil samples are presented in Table 1. Soil textural classes were distributed among the sites as follows: The soil of nine sites was Clay Loam (CL), four sites Sandy Clay 
Loam (SCL), one site Clay soil (C) and one Loam (L). In other words, generally the soils were of medium to light texture by $93.33 \%$.

Also, according to the above Table 1, the soil pH of twelve sites was acidic varying between 6.06-5.25, while of three sites it was basic (alkaline) ranging from 7.00 to 7.65 . The organic matter (OM) was distributed as follows: Eight sites contained $>3.00 \%$ varying from $3.07-3.68 \%$, six sites $>2.00 \%$ varying from $2.04-2.93 \%$ and one site $>1.00$ being $1.97 \%$. Also, the soil electrical conductivity (EC) of all sites studied, was within the normal range $<1.5 \mathrm{mS} \mathrm{cm}^{-1}$. As far as the mean plant nutrient content of the soils under consideration, it varied for all the sites studied as follows: $\mathrm{P} 7.33-26.11 \mathrm{mg} \mathrm{kg}^{-1}, \mathrm{~K} 47.25-110.25 \mathrm{mg} \mathrm{kg}^{-1}$, Mg 121.75-298.75 $\mathrm{mg} \mathrm{kg}^{-1}$, and Ca 858.75- >2000 $\mathrm{mg} \mathrm{kg}^{-1}$ (Table 2).

Table 1. Characteristics of soil samples per site

\begin{tabular}{ccccccccc}
\hline Sample site* & pH & $\mathrm{CaCO}_{3}$ (\%) & EC & O.M. (\%) & Sand (\%) & Silt (\%) & $\begin{array}{c}\text { Clay } \\
\text { (\%) }\end{array}$ & $\begin{array}{c}\text { Mean } \\
\text { texture }\end{array}$ \\
\hline 1 & 7.65 & 13.90 & 0.613 & 1.97 & 28.0 & 38.0 & 34.0 & $\mathrm{CL}$ \\
\hline 2 & 6.06 & 3.20 & 0.489 & 3.07 & 42.5 & 28.5 & 29.0 & $\mathrm{CL}$ \\
\hline 3 & 5.25 & - & 0.266 & 2.93 & 34.5 & 35.5 & 30.0 & $\mathrm{CL}$ \\
\hline 4 & 5.40 & - & 0.357 & 3.43 & 42.5 & 35.0 & 22.5 & $\mathrm{CL}$ \\
\hline 5 & 5.75 & - & 0.823 & 3.07 & 38.0 & 36.0 & 26.0 & $\mathrm{CL}$ \\
\hline 6 & 5.84 & - & 0.929 & 3.34 & 37.5 & 36.5 & 26.0 & $\mathrm{CL}$ \\
\hline 7 & 7.00 & 23.03 & 0.901 & 2.84 & 48.5 & 29.5 & 22.0 & $\mathrm{SCL}$ \\
\hline 8 & 5.58 & - & 0.430 & 3.01 & 35.0 & 34.0 & 31.0 & $\mathrm{CL}$ \\
\hline 9 & 5.88 & - & 1.161 & 2.54 & 47.0 & 27.0 & 26.0 & $\mathrm{SCL}$ \\
\hline 10 & 5.65 & - & 0.335 & 3.28 & 34.0 & 32.0 & 34.0 & $\mathrm{CL}$ \\
\hline 11 & 5.75 & - & 0.500 & 3.66 & 35.0 & 34.5 & 30.5 & $\mathrm{CL}$ \\
\hline 12 & 5.35 & - & 0.347 & 3.68 & 36.5 & 37.0 & 26.5 & $\mathrm{C}$ \\
\hline 13 & 5.63 & - & 0.361 & 2.80 & 46.0 & 29.0 & 25.0 & $\mathrm{SCL}$ \\
\hline 14 & 5.36 & - & 0.443 & 2.04 & 46.0 & 25.5 & 28.5 & $\mathrm{SCL}$ \\
\hline 15 & 7.73 & 37.88 & 0.490 & 2.04 & 38.5 & 36.5 & 25.0 & $\mathrm{~L}$ \\
\hline
\end{tabular}

* site as they are presented on Fig 1

Table 2. Mean concentration and range $\left(\mathrm{mg} \mathrm{kg}^{-1}\right)$ of $\mathrm{P}, \mathrm{K}, \mathrm{Mg}$ and $\mathrm{Ca}$ in soil samples per site

\begin{tabular}{ccccccccc}
\hline $\begin{array}{c}\text { Sample } \\
\text { site* }\end{array}$ & \multicolumn{3}{c}{$\mathbf{P}$} & \multicolumn{2}{c}{$\mathbf{K}$} & \multicolumn{2}{c}{$\mathbf{M g}$} & \multicolumn{2}{c}{ Ca } \\
\cline { 2 - 9 } & Mean & Range & Mean & Range & Mean & Range & Mean & Range \\
\hline 1 & 10.42 & $6.05-17.92$ & 80.00 & $59-109$ & 298.75 & $167-546$ & $>2000$ & $>2000$ \\
\hline 2 & 26.11 & $6.88-60.39$ & 110.25 & $39-189$ & 150.00 & $125-196$ & 1426.00 & $889-2000$ \\
\hline 3 & 24.65 & $11.41-51.00$ & 99.00 & $65-112$ & 131.00 & $101-148$ & 1009.25 & $889-2000$ \\
\hline 4 & 22.12 & $15.9-26.29$ & 60.00 & $29-84$ & 128.25 & $111-152$ & 1103.25 & $675-1782$ \\
\hline 5 & 22.33 & $8.35-35.63$ & 78.00 & $55-124$ & 128.50 & $101-177$ & 1120.75 & $652-2000$ \\
\hline 6 & 24.82 & $11.73-49.99$ & 72.50 & $59-93$ & 135.00 & $95-175$ & 1342.25 & $946-2000$ \\
\hline 7 & 11.57 & $7.67-15.93$ & 72.50 & $45-97$ & 131.25 & $123-144$ & 1738.25 & $953-2000$ \\
\hline 8 & 21.32 & $15.04-29.34$ & 47.25 & $42-53$ & 124.75 & $118-132$ & 1229.75 & $910-2000$ \\
\hline 9 & 24.28 & $14.87-31.42$ & 49.50 & $35-69$ & 130.00 & $100-184$ & 1396.25 & $721-2000$ \\
\hline 10 & 20.77 & $12.33-35.54$ & 147.5 & $59-295$ & 156.00 & $116-204$ & 1212.50 & $1070-1397$ \\
\hline 11 & 14.19 & $9.46-18.60$ & 98.25 & $54-165$ & 139.50 & $116-157$ & 1356.25 & $925-2000$ \\
\hline 12 & 25.73 & $18.57-42.56$ & 90.00 & $70-128$ & 121.25 & $110-126$ & 858.75 & $781-1031$ \\
\hline 13 & 12.92 & $6.49-15.97$ & 84.00 & $68-110$ & 125.50 & $105-135$ & 1085.50 & $1017-1241$ \\
\hline 14 & 15.89 & $8.30-32.64$ & 56.50 & $48-71$ & 169.75 & $92-232$ & 1224.50 & $593-2000$ \\
\hline 15 & 7.33 & $6.53-8.07$ & 73.00 & $49-95$ & 153.25 & $141-160$ & $>2000$ & $>2000$ \\
\hline
\end{tabular}

*site as they are presented on Fig 1 


\subsection{Heavy metal concentrations}

The mean concentration and the range of heavy metals of soil samples of the 15 sites are reported in Table 3. It can be seen that $\mathrm{Mn}$ has the highest concentration, being $80.622 \mathrm{mg} \mathrm{kg}^{-1}$ and ranging between 5.33 and $259.30 \mathrm{mg} \mathrm{kg}^{-1}$.

Also in Table 4 the mean concentration of each heavy metal is reported per site studied. According to Kabata-Pendias (2010) higher Mn levels are often reported for soils over mafic rocks and for soils rich in Fe and/or organic matter, and also for soils from arid or semiarid regions. In the present study, it was found that the DTPA extractable soil Mn concentration increased with the increase of the DTPA extractable Fe (Figure 2). This result seems to be in line with the conclusion reported by Kabata-Pendias (2010), according to which Mn soil levels are higher in soils rich in Fe.

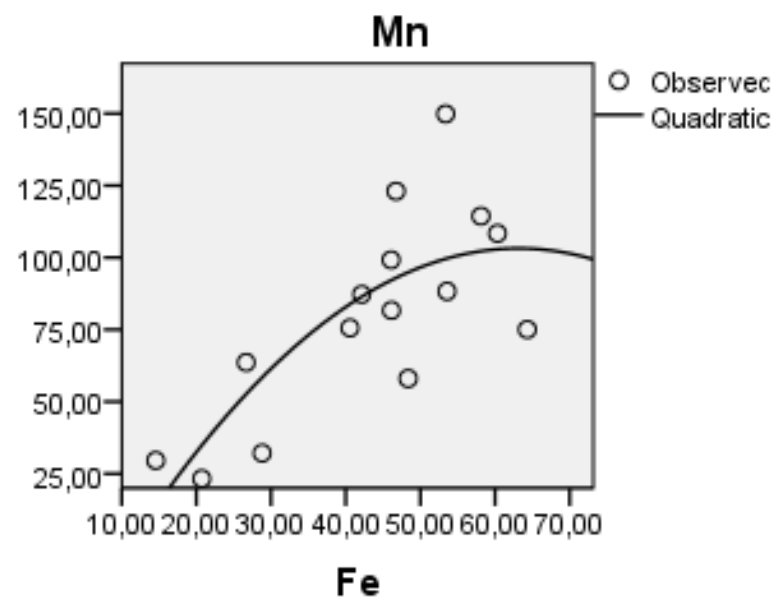

Figure 2: DTPA extractable $\mathrm{Mn}\left(\mathrm{mg} \mathrm{kg}^{-1}\right.$ soil) accumulation in soil as affected by the soil DTPA extractable $\mathrm{Fe}$ ( $\mathrm{mg} \mathrm{kg}^{-1}$ soil). Obviously the $\mathrm{Mn}$ interacts synergistically with the $\mathrm{Fe}$

Table 3. Mean concentrations of heavy metal in soil per site $\left(\mathrm{mg} \mathrm{kg}^{-1}\right)$

\begin{tabular}{cccccccccc}
\hline $\begin{array}{c}\text { Sample } \\
\text { site* }\end{array}$ & Fe & $\mathbf{Z n}$ & $\mathbf{M n}$ & $\mathbf{C u}$ & $\mathbf{C d}$ & $\mathbf{C o}$ & $\mathbf{C r}$ & $\mathbf{N i}$ & $\mathbf{P b}$ \\
\hline 1 & 20.714 & 0.830 & 23.257 & 16.522 & 0.037 & 0.177 & 0.014 & 0.738 & 1.233 \\
\hline 2 & 28.805 & 3.588 & 32.120 & 2.659 & 0.030 & 0.167 & 0.014 & 0.237 & 1.482 \\
\hline 3 & 46.080 & 2.402 & 99.223 & 9.970 & 0.052 & 0.565 & 0.014 & 0.413 & 1.911 \\
\hline 4 & 53.561 & 2.039 & 88.286 & 2.998 & 0.045 & 0.419 & 0.014 & 0.414 & 2.303 \\
\hline 5 & 46.131 & 1.489 & 81.677 & 2.248 & 0.043 & 0.360 & 0.014 & 0.319 & 1.003 \\
\hline 6 & 64.310 & 1.907 & 75.047 & 2.977 & 0.048 & 0.400 & 0.014 & 0.547 & $3 . .090$ \\
\hline 7 & 26.672 & 1.716 & 63.601 & 5.580 & 0.076 & 0.414 & 0.014 & 1.049 & 1.105 \\
\hline 8 & 42.154 & 1.362 & 87.243 & 3.202 & 0.045 & 0.564 & 0.014 & 0.487 & 1.219 \\
\hline 9 & 40.571 & 1.456 & 75.561 & 5.410 & 0.044 & 0.503 & 0.014 & 1.433 & 1.432 \\
\hline 10 & 53.383 & 2.130 & 149.874 & 3.912 & 0.061 & 0.705 & 0.014 & 0.475 & 1.492 \\
\hline 11 & 46.744 & 1.940 & 123.030 & 4.040 & 0.070 & 0.510 & 0.014 & 0.585 & 1.177 \\
\hline 12 & 60.115 & 2.206 & 108.394 & 4.588 & 0.066 & 0.504 & 0.014 & 0.532 & 3.179 \\
\hline 13 & 58.165 & 2.980 & 114.397 & 8.800 & 0.051 & 0.769 & 0.014 & 1.157 & 2.453 \\
\hline 14 & 48.361 & 2.585 & 58.041 & 6.950 & 0.048 & 0.739 & 0.016 & 1.556 & 3.384 \\
\hline 15 & 14.653 & 1.298 & 29.582 & 4.552 & 0.064 & 0.301 & 0.014 & 1.318 & 0.817 \\
\hline
\end{tabular}

*site as they are presented on Fig 1 


\subsection{Interactions between heavy metals, plant nutrients, and soil chemical and physical properties}

In the present study, it was found that a considerable number of interactions are taking place in the soil system between heavy metals, essential macro and micronutrients ( $\mathrm{P}, \mathrm{K}, \mathrm{Ca}, \mathrm{Mg}, \mathrm{Mn}, \mathrm{Fe}, \mathrm{Zn}$, and $\mathrm{Cu}$ ) , and physical and chemical properties of the soil, such as, $\mathrm{OM}, \mathrm{EC}, \mathrm{pH}$, and calcium carbonate.

In Figure 3, the statistically significant interactions are presented. As shown in Table 4, in total, 92 statistically significant interactions were found to occur in the sites studied. Of these interactions 59 or $64.13 \%$ are synergistic, and only 33 or $35.87 \%$ are antagonistic, suggesting a net supply of heavy metals to soil and [plant nutrients. Quantification of the elemental contribution by all the interactions included

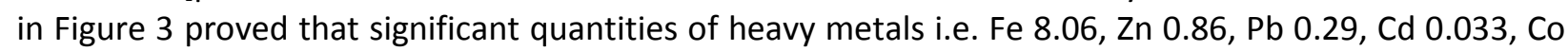
0.112 and $\mathrm{Ni} 0.125, \mathrm{~kg} / \mathrm{ha}$ and plant nutrients i.e $\mathrm{P}_{2} \mathrm{O}_{5} 8.6, \mathrm{~K}_{2} \mathrm{O} 52.92$ and $\mathrm{Ca} 78.98 \mathrm{~kg} / \mathrm{ha}$, have been added to soil, available for plant growth (Table 5).

The above contribution of the elemental interactions to soil has been reported as a means to explain the observed situation where in certain cases, heavy metals behave as plant nutrients (Kalavrouziotis and Koukoulakis, 2012).

\begin{tabular}{|c|c|c|c|c|c|c|c|c|c|c|c|c|c|c|c|c|c|}
\hline \multirow{2}{*}{\multicolumn{2}{|c|}{ (indep $\mathrm{x}$ dep) }} & \multicolumn{16}{|c|}{ independent } \\
\hline & & $\mathbf{P}$ & $\mathbf{K}$ & Ca & $\mathrm{Mg}$ & Mn & $\mathbf{Z n}$ & $\mathbf{F e}$ & $\mathbf{C u}$ & Cd & Co & $\mathbf{N i}$ & $\mathbf{P b}$ & $\mathrm{CaCO}_{3}$ & pH & OM & Clay \\
\hline \multirow{12}{*}{$\begin{array}{l}\mathrm{d} \\
\mathrm{e} \\
\mathrm{p} \\
\mathrm{e} \\
\mathrm{n} \\
\mathrm{d} \\
\mathrm{e} \\
\mathrm{n} \\
\mathrm{t}\end{array}$} & $\mathbf{P}$ & & & 1 & 1 & & & & & & & & & & & & \\
\hline & $\mathbf{K}$ & & & & & & & & & & & & & & & & \\
\hline & Ca & I & & & | & & & 1 & & & 1 & & & & & & \\
\hline & Mg & & & & & | & 1 & | & & & | & & & & & & \\
\hline & Mn & & & & I & & & & & & 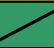 & & & & & & \\
\hline & $\mathrm{Zn}$ & & & & & & & & & 1 & & & & & & & \\
\hline & $\mathrm{Fe}$ & | & & & I & & & & & 1 & & & & & & & \\
\hline & $\mathbf{C u}$ & & & & & & & & & & & & & & & & \\
\hline & Cd & & & & & & & & | & & & & & & & & \\
\hline & Co & & & & & & & & 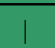 & & & & & & & & \\
\hline & $\mathbf{N i}$ & & & & & & & & & & & & & & & & \\
\hline & $\mathbf{P b}$ & & & & & & & & & & & & & & 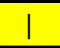 & & \\
\hline
\end{tabular}

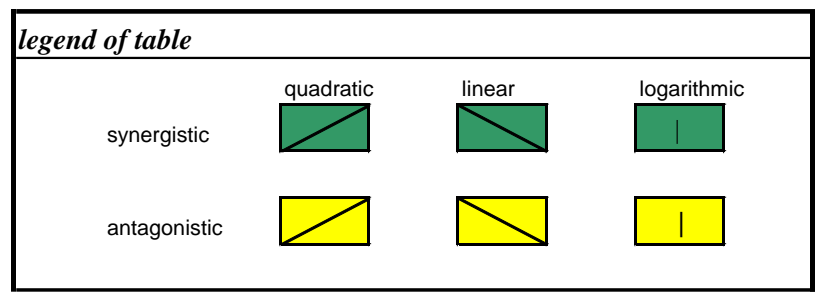

Figure 3: Total statistically significant number of interactions occurring in the soils samples

Table 4. Percent distribution of statistically significant interactions occurring in the soils of the sites studied according to the type and the type interaction and kind of regression equation

\begin{tabular}{ccccc}
\hline \multirow{2}{*}{ Type of interaction } & \multicolumn{3}{c}{ Kind of regression equation } & \multirow{2}{*}{ Total (\%) } \\
\cline { 2 - 4 } & Quadratic & Linear & Logarithmic & \\
\hline Synergistic & $25(27.17)$ & $15(16.30)$ & $19(29.65)$ & $59(64.19)$ \\
\hline Antagonistic & $18(19.56)$ & $3(3.26)$ & $12(13.04)$ & $33(35.86)$ \\
\hline Total & $43(46.74)$ & $18(19.56)$ & $31(33.70)$ & $92(100)$ \\
\hline
\end{tabular}

The numbers in parentheses refer to the percent distribution. 
Table 5. Elemental contribution to soils by the elemental interactions occurring in the sites studied

\begin{tabular}{ccccc}
\hline Element & PEC \% & Interaction's elemental contribution $\left(\mathbf{m g ~ k g}^{-\mathbf{1}}\right)$ & \multicolumn{2}{c}{$\mathbf{~ k g} / \mathbf{h a}$} \\
\hline $\mathbf{P}$ & 13.69 & 2.595 & 3.75 & $\mathrm{P}$ \\
\hline $\mathbf{K}$ & 37.30 & 30.292 & 43.94 & $\mathrm{~K}$ \\
\hline $\mathbf{C a}$ & 4.03 & 54.06 & 78.39 & $\mathrm{Ca}$ \\
\hline $\mathbf{F e}$ & 12.83 & 5.564 & 8.06 & $\mathrm{Fe}$ \\
\hline $\mathbf{Z n}$ & 29.98 & 0.598 & 0.86 & $\mathrm{Zn}$ \\
\hline $\mathbf{M n}$ & 8.15 & 6.659 & 9.53 & $\mathrm{Mn}$ \\
\hline $\mathbf{C d}$ & 46.96 & 0.023 & 0.033 & $\mathrm{Cd}$ \\
\hline $\mathbf{C o}$ & 16.33 & 0.077 & 0.112 & $\mathrm{Co}$ \\
\hline $\mathbf{C r}$ & -14.29 & -0.002 & -0.0029 & $\mathrm{Cr}$ \\
\hline $\mathbf{N i}$ & 39.13 & 0.293 & 0.125 & $\mathrm{Ni}$ \\
\hline $\mathbf{P b}$ & 11.30 & 0.205 & 0.297 & $\mathrm{~Pb}$ \\
\hline
\end{tabular}

3.4. The quantification of the elemental contribution of heavy metals interaction with plant nutrients and soil physical and chemical properties

The present study evaluated quantitatively the contribution of the elemental interactions occurring in the soil by applying the procedure by based on the analytical data of the soils studied Koukoulakis et al., (2013). Thus, the statistically significant interactions were determined by means of regression analysis, (Figure 3.) The regression equations obtained were used for the quantification of the elemental contribution.

However, as this contribution is affected by the soil physical and chemical properties, $\{\mathrm{pH}$, Clay, Electrical conductivity $(\mathrm{EC})$, Organic matter $(\mathrm{OM})$ \}, the effect of each of these soil properties on the elemental quantification of heavy metals, was thoroughly studied as follows:

One basic aim of the present work was to study and evaluate the overall effect of each of the above mentioned soil properties on the interaction's elemental contribution. Taking into account that the present study was based on only soil sampling, where no systematic variables were applied, in order to study the effect of soil properties, it was necessary to divide the data of each property into three ranges as follows:
a- $\mathrm{pH}$
4.62-5.99,
6.00-6.99,
7.00-7.88.
b- $\mathrm{OM}(\%)$
1.02-2.07,
2.08-2.99,
3.00-4.77
c- Clay(\%)
14-22
23-29,
30-56
d- $E C\left(\mathrm{mS} \mathrm{cm}^{-1}\right)$
0.157-0.289,
0.290-0.599,
0.600-2.302

Following the above introductory statements, the effect of the above three ranges of each soil property on the quantified levels of each heavy metal and plant nutrient, is examined below.

\subsubsection{Effect of $\mathrm{pH}$}

It can be seen in Figure 4, that the elemental contribution of interactions, in terms of heavy metals and plant nutrients, expressed as PEC, is positive for the $90 \%$ of the elements studied. More specifically, the elements $\mathrm{Fe}, \mathrm{Cu}, \mathrm{Mn}$, and $\mathrm{Ni}$ were contributed positively and at an increasing rate under all the three $\mathrm{pH}$ ranges.

Also the concentration of the contributed elements $\mathrm{Mg}, \mathrm{Ca}, \mathrm{Co}$, and $\mathrm{Pb}$ increased, but only under the low and medium range of $\mathrm{pH}$, decreasing or being non significant under the higher range.

Similarly, the elements $\mathrm{Cd}$ and $\mathrm{Pb}$ were contributed positively, but only under the low and the higher $\mathrm{pH}-$ range, being non significant under the medium range. On the other hand $\mathrm{Zn}$ remained constant, not being affected by the three $\mathrm{pH}$-ranges studied

Thus, it can generally be concluded that the PEC was increased significantly under the effect of the $\mathrm{pH}$, suggesting that the increase of $\mathrm{pH}$ within the limits of the experimental data, i.e. 4.52 to 7.88 favoured 
the occurrence of synergistic interactions. This conclusion is in line with the data of Table 5 where the numbers of synergistic interactions are almost twice as those of the antagonistic ones.

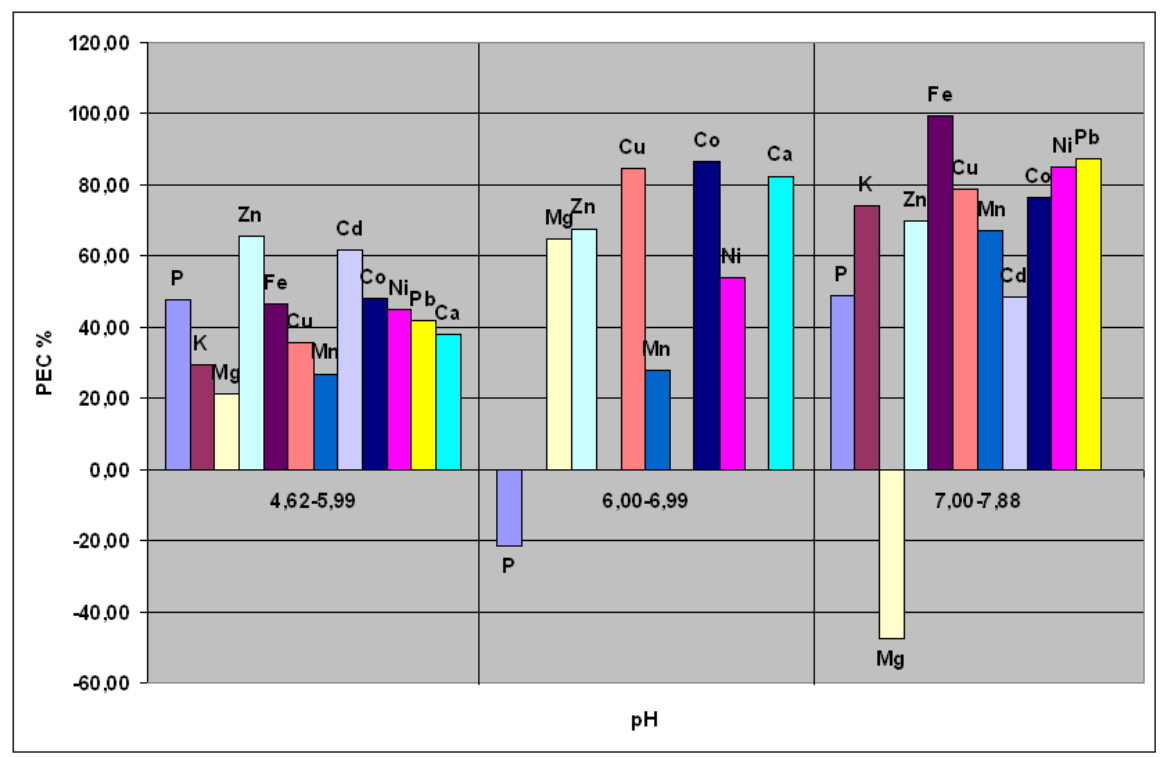

Figure 4: The effect of three $\mathrm{pH}$-ranges on the percent elemental contribution to soils samples

\subsubsection{Effect of organic matter}

The effect of organic matter (OM) on the interaction's elemental contribution, under the three ranges studied was found to be negative for the $90 \%$ of the elements examined (Figure 5). Thus, the contributed levels of the heavy elements, $\mathrm{Zn}, \mathrm{Mn}, \mathrm{Cd}$ and $\mathrm{Ni}$ decreased with increase of the $\mathrm{OM}$, while the $\mathrm{Fe}$ and $\mathrm{Co}$ contribution was more or less unaffected under the above ranges, while the contribution in terms of the $\mathrm{Pb}$ concentration was erratic and not definite.

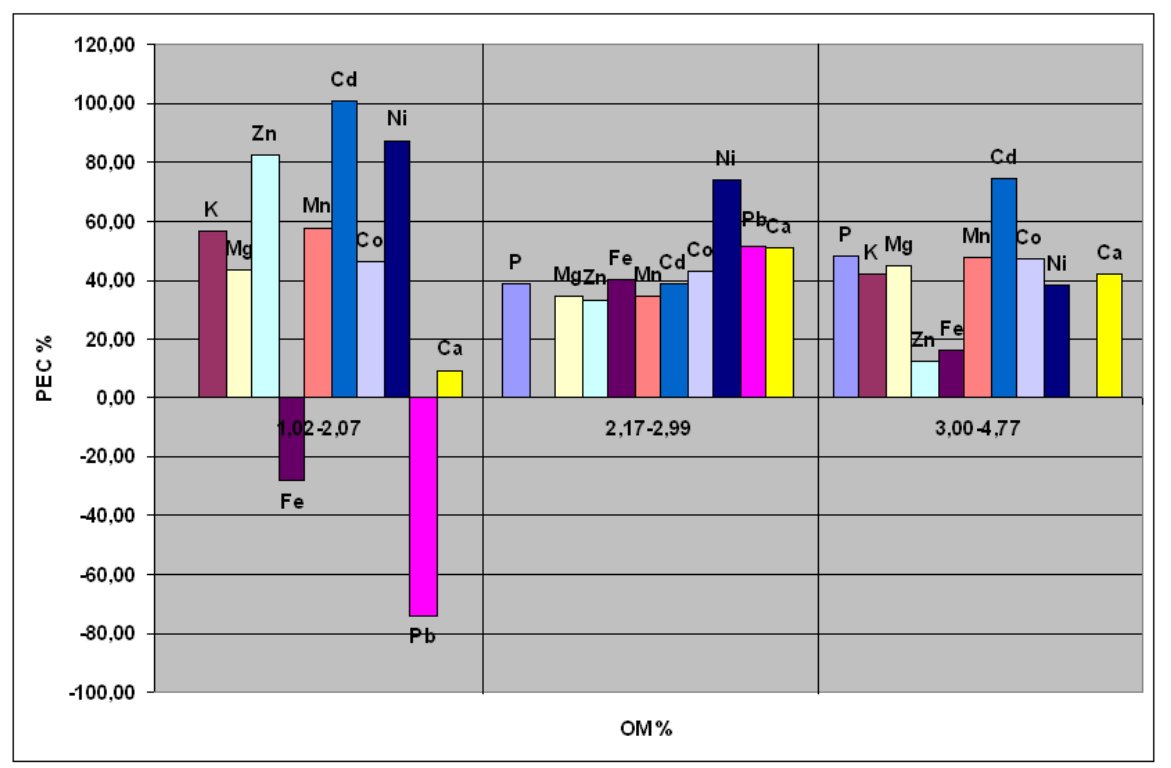

Figure 5. The effect of three OM-ranges on the percent elemental contribution to soils samples

It was inferred that the OM in general, did not favour the occurrence of synergistic interactions. This result may possibly be due to the high absorbing capacity of organic matter for the interacting elements, due to the high concentration of $\mathrm{OM}$ in ligands or functional units such as $-\mathrm{COOH}$, phenolic $-\mathrm{OH}, \mathrm{C}=\mathrm{O}$ etc 
(Stevenson and Cole, 1999), which form complex compounds with metals, thus creating unbalanced conditions between the interacting elements. It must be underlined that the interactions between elements are a dynamic procedure and may change between synergism and antagonism, under the effect of many factors, including the level of the concentration of the interacting elements.

\subsubsection{Effect of clay}

The effect of clay on PEC is given in Figure 6. Careful examination of this Figure reveals the following: The elemental contribution in terms of $\mathrm{Ni}, \mathrm{Fe}$ and $\mathrm{Zn}$, and $\mathrm{P}$, under the effect of the three clay ranges increased significantly while that of $\mathrm{Cd}$ increased under the effect of the low and highest range. Conversely, the contribution in $\mathrm{Cu}$ and $\mathrm{Co}$, decreased respectively under all clay ranges, studied.

The contribution in $\mathrm{K}, \mathrm{Mg}$ and $\mathrm{Mn}$ was not affected by the clay ranges, while $\mathrm{Pb}$ and $\mathrm{Ca}$ were contributed in an erratic way. Finally, the contribution in $\mathrm{K}$ was unaffected by the changes of clay level.

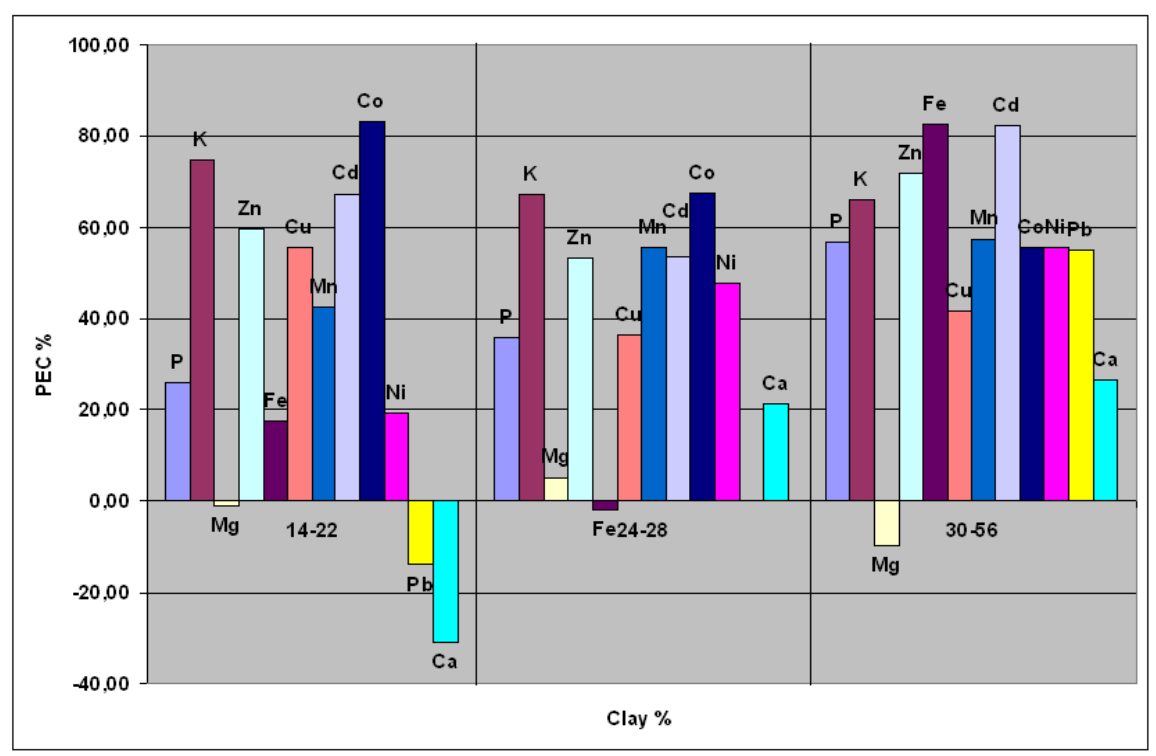

Figure 6: The effect of three Clay-ranges on the percent elemental contribution to soils samples

\subsubsection{Effect of electrical conductivity}

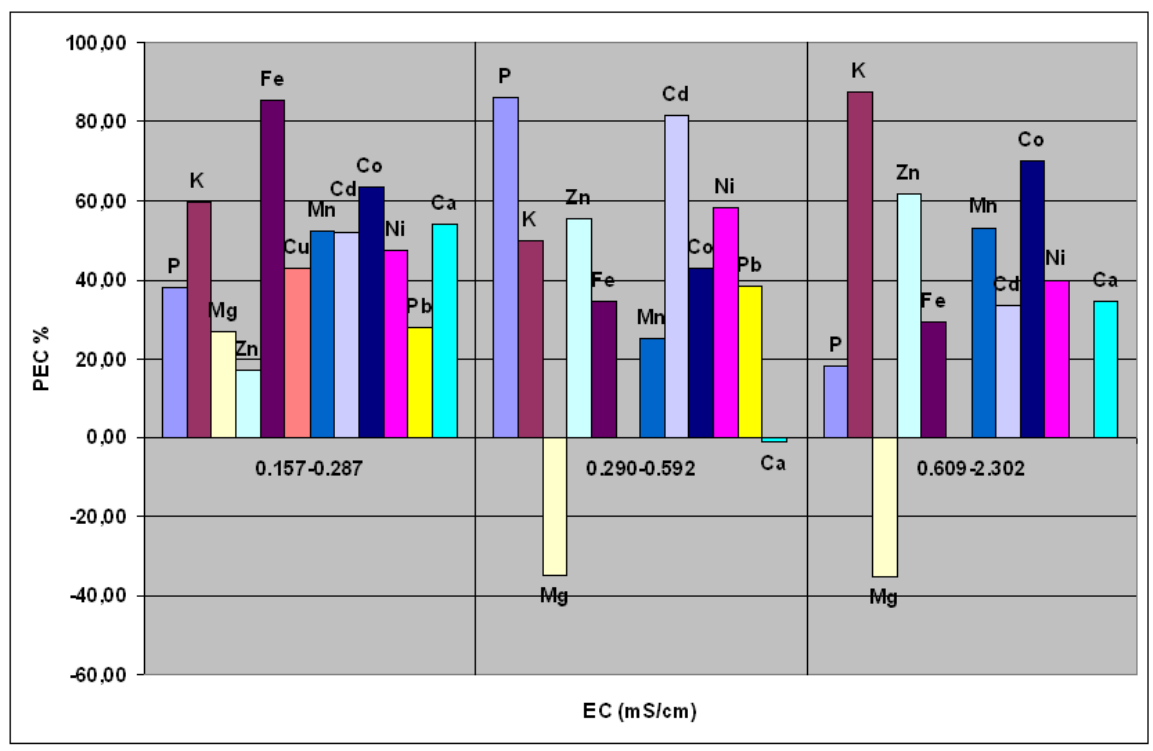

Figure 7. The effect of three EC-ranges on the percent elemental contribution to soils samples 
The PEC under the effect of the EC was negative in most of the metals studied, suggesting that antagonism was the controlling factor of the elemental interactions occurring in the soil in presence of varying EC levels.

As indicated in Figure 7, only the elements $\mathrm{K}$ and $\mathrm{Zn}$ were contributed positively, increasing under the effect of the three $\mathrm{EC}$ ranges, respectively. Also, the contribution in $\mathrm{Pb}, \mathrm{Cd}, \mathrm{P}$, and $\mathrm{Ca}$ increased under the effect of the low and medium range, decreasing under the highest level. On the other hand, all the remaining elements were negatively contributed, decreasing with the increase of the EC ranges. Thus, $\mathrm{Fe}$, $\mathrm{Ni}$, and $\mathrm{Cu}$ contribution decreased significantly by the increasing EC levels, while the contribution in Co was more or less not affected by the three ranges of the EC studied.

\section{Conclusions}

Based on the aforementioned, the following conclusions could be drawn:

Most of the elemental interactions (64.19\%) occurring in the soils studied were synergistic whereas $35.86 \%$ of them were antagonistic.

The soil properties affected the percent elemental contribution (PEC), as follows:

(i)- $\mathrm{pH}$ increased significantly the PEC in term of heavy metals and plant nutrients of almost all elements,

(ii)- Organic matter did not seem to favor the PEC, as it had a negative effect on the elemental contribution of most elements,

(iii)- Soil clay increased the contribution only in terms of $\mathrm{P}, \mathrm{Fe}, \mathrm{Ni}$, and $\mathrm{Zn}$, and

(iv)- The electrical conductivity had a negative effect on the elemental contribution of most heavy metals and plant nutrients, with the exception of $\mathrm{K}$ and $\mathrm{Zn}$ which were contributed positively

(v)- It was concluded that the elemental interactions contribution in terms of heavy metals, occurring perpetually in soil, constitute a source of a "silent" and imperceptible pollution, which may possibly become in the long run a serious threat, by complementing and enhancing possible anthropogenic metal inputs in soil, thus, potentially accelerating future soil and environmental pollution.

\section{References}

Bouyoucos, G. H. (1951). A recalibration of the hydrometer method for making mechanical analysis of soils. Agronomy Journal, 43, 434-438.

Jackson M.L. (1958). Soil chemical analysis. Englewood Cliffs, NJ: Prentice Hall.

Institute of Geology and Mineral Exploration, (2003). Geological map of Elia Prefecture, Peloponnese, Greece - Map 9. Project (EU No. 4215 - I.G.M.E. No. 9561962).

Kabata-Pendias A. (1993), Behavioural properties of trace metals in soils. Applied Geochemistry, 2, 3-9.

Kabata-Pendias A. (2010), Trace Elements in Soils and Plants, 4th edn. CRC Press, USA.

Kabata-Pendias A. and Andriano D.C. (1995), Trace metals. Soil amendments and environmental quality (J. E. Rechcigl Ed.). Boca Raton, FL, USA: CRC Lewis.

Kalavrouziotis I.K., Koukoulakis P.H., Robolas P., Papadopoulos A.H. and Pantazis V.P. (2008), Interrelationships of heavy metals Macro and Micronutrients and properties of soil cultivated with Brassica oleracea var Italica (Broccoli), under the effect of treated municipal wastewater, Water, Air, Soil Pollut., 190:309-321

Kalavrouziotis I.K. and Koukoulakis P.H. (2009), Distribution of elemental interactions in Brussels sprouts plants, under the Treated Municipal Wastewater, Journal of Plant Interactions, 4(3), 219-231.

Kalavrouziotis I.K., Koukoulakis P.H. and Mehra A. (2010), Quantification of elemental interaction effects on Brussels sprouts under treated municipal wastewater, Desalination, 254, 6-11.

Kalavrouziotis I.K. and Koukoulakis P.H. (2012), Contribution of elemental interactions in total essential nutrients and heavy metal content in cabbage under treated wastewater irrigation, Plant biosystems, 146(3), 491-499. 
Koukoulakis P., Chatzissavvidis C., Papadopoulos A. and Pontikis D. (2013), Interactions between leaf macronutrients, micronutrients and soil properties in pistachio (Pistacia vera L.) orchards, Acta Botanica Croatica, 72(2), 295-310.

Lanyon L. E. and Heald W.R. (1982), Magnesium, calcium strontium, and barium. In A. L. Page et al. (Eds.), Methods of soil analysis part 2. Madison: ASA.

Lindsay W.L. and Norvell W.A. (1978), Development of DTPA micronutrient soil test for zinc, iron manganese and copper, Soil Science Society of American Journal, 42, 421-428.

Ntzala G., Koukoulakis P.H., Papadopoulos A.H., Leotsinidis M., Sazakli E. and Kalavrouziotis I.K. (2013), Interrelationships of pollution load index, transfer factor and concentration factor under the effect of sludge, Environmental Monitoring and Assessment, 185(6), 5231-5242.

Olsen S.R., Cole C.V., Watanabe F.S. and Dean L.A. (1954), Estimation of available phosphorus in soils by extraction with sodium bicarbonate, USDA Circular Number 939. Washington DC: U.S. Government Printing Office.

Richards I.A. (1954), Diagnosis and improvement of alkaline and sodic soils. Agric. Handbook No 60. Washington DC: USDA.

Soltanpour P.N., Johnson C.W., Workman S.M., Jones J.B.Jr. and Miller R.O. (1998), Advances in ICP emission and ICP mass spectroscopy, Advances in Agronomy, 64, 28-113.

Stevenson F.J. and Cole M.A. (1999), Cycles of Soils: Carbon, Nitrogen, Phosphorus, Sulfur, Micronutrients, 2nd Edition. New York: Wiley. 